Biology | Susan Canney

\title{
Action research creates a shared future for elephants and humans
}

In 2009 a crisis faced the elephant and human populations of central Ma when a vital fresh water source dried up. Reduced rainfall and increased human domestic cattle contributed to this critical problem $\mathrm{Dr}$ Susan Canney of the University of Oxford and Director of the Mali Elephant Project, decided a new and prompt approach was needed if elephants and humans were to coexist in the future. Action research to target the underlying proba has created a successful and sustainable solution for both elephants and humans.

$\triangle \begin{aligned} & \text { cross West Africa, threats from } \\ & \text { habitat loss and degradation, }\end{aligned}$ an increased human population, competition with domesticated livestock and intense poaching have left elephant vopulations small, rfagmented and internationally important populstion of around 300 individuals that is remarkable for having evolved a unique migration circuit across the region which allows the elephants to survive an environment where the resources they need are highly variable across seasons, and often separated by large distances. Dr Susan Canney is the Director of the Mali Elephant Project, which was created in 2007 to find ways for humans and elephants to thrive together. This is a complex social-ecological system, but despite this, the vision of the project was to enable beneficial and sustainable

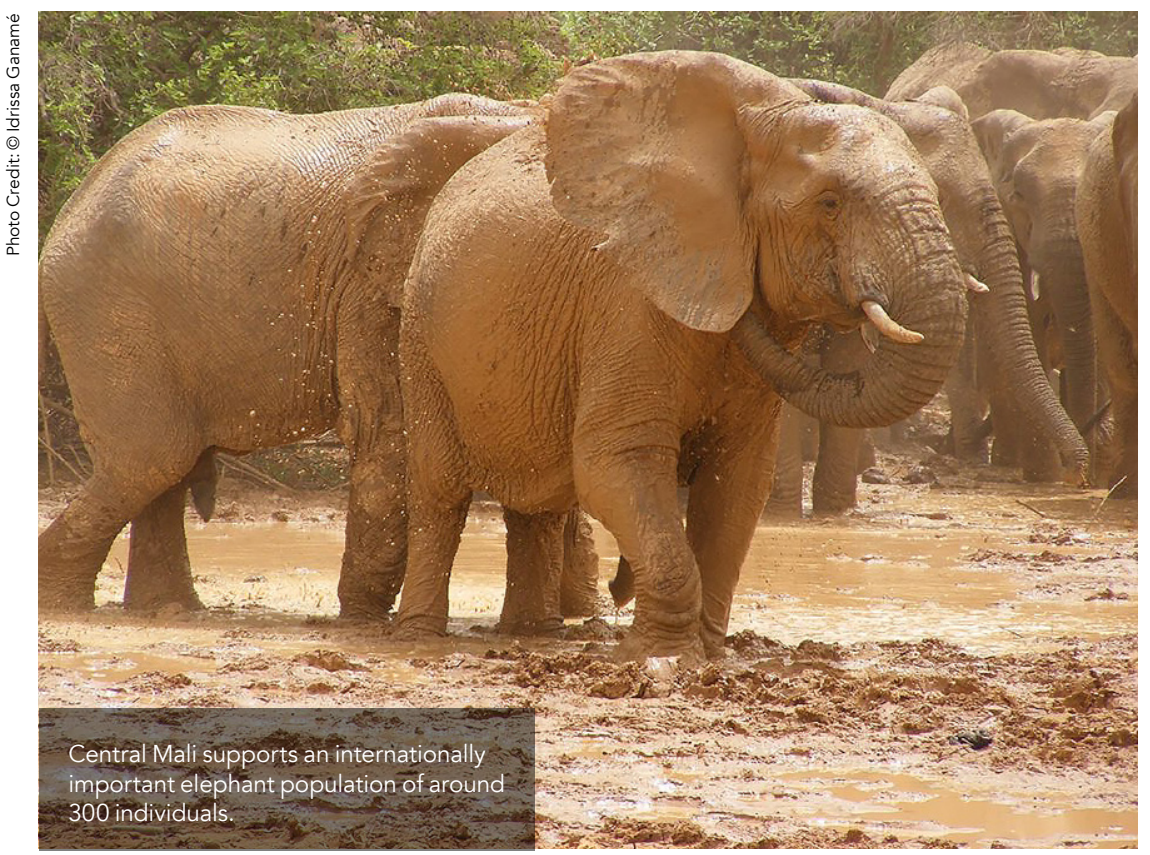

\section{DESERT-ADAPTED}

AFRICAN ELEPHANTS

Analyses using Save the Elephants' GPS collar data to track the elephants' movements have revealed the full extent this population, covering $32,000 \mathrm{~km}^{2}$ (n) area the size of Belgium and Luxembourg combined) the largest ever recorded for elephants. By combining the GPS data with satellite imagery, climate and land use data, it was possible to piece together an understanding of why the elephants behave in this unique way. The territory and migration circuit of this population sits within the Sahel, which is a transition zone in terms of geography and ecology, between the Sahara in the north and the Savanna in the south. The climate is a constant intense heat with a long dry season and a short irregular rainy season. The GPS data showed that the elephants' behaviour allowed them to deal with the spending $95 \%$ of . avel ver quickly During the dy season the elephats remin in the drerth seaso region where there are lakes surrounded by thicket forest which they stay close to, then move between as each dries up. In contrast during the rainy season the elephants are no longer restricted by access to water and migrate further south to take advantage of abundant and varied forage, all the while avoiding human activity where possible.

\section{HUMAN-ELEPHANT CONFLICT} As well as the elephant population, this region of southern Mali contains a diverse group of ethnicities and communities using the land and other natural resources for their livelhoods, from to agriculture and irrigated gardens. In addition, large herds of catle belonging use of the water and pasture. As the competition for vital resources slowly intensified, human-elephant conflict resolution became an increasing priority. However, the vast physical area involved and a lack of resources and political will to tackle the problem made this a daunting task. The elephants moved through an immense, open, populated landscape and so once the GPS collar studies had been completed, the research question became: "What does it take to turn a situation from one of threat to elephants to one where they can thrive? It was difficult to know what to do.

A significant break-through came during a serendipitous conversation with a local the elephants disappeared the villager responded: "If elephants disappear it means the environment is no longer good for us." This answer revealed how both the conservation team and the local communities understood that the elephants are a vital indicator of the ecosystem's health. The Mali Eleph Project used this as a starting point to build a shared vision of an environment both elephants and humans.

\section{CRISIS POINTS}

In 2009 Lake Banzena, the largest lake in the region, dried up before the rains arrived, and human-elephant conflict focus. Adding to his in 2012 a corp destabilised the country with arie numbers of young men recruited to join armed groups Poaching for ivony erupted as traffickers and armed groups profited from the governance vacuum.

Looking back, Dr Canney reflects that each time a crisis struck, not knowing what to do meant a new approach was needed to find a solution.
Historically, conservation has focused Historically, conservation has focused on strictly protecting land. However, this approach was not possible for such a large populated area, where complex suite of economic and socia factors had led to overexploitation of natural resources, and conflict betwe humans and
elephants.

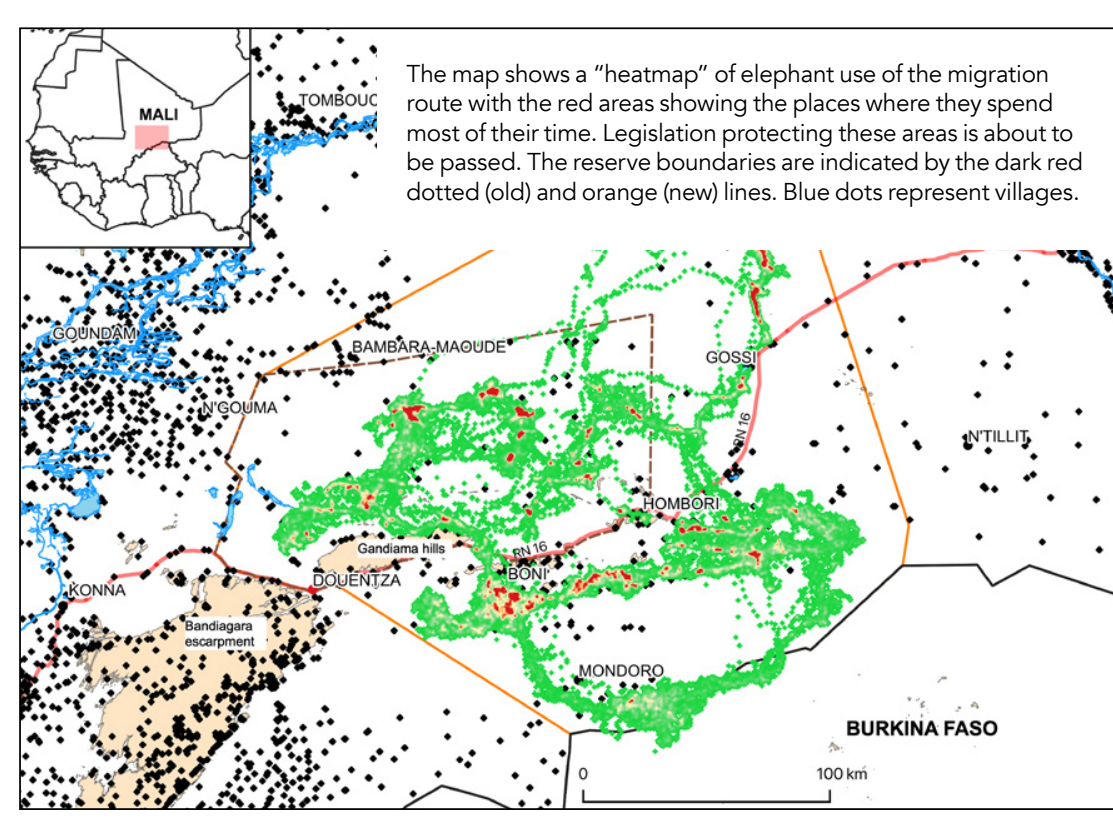

If elephants disappear it means the environment is no longer good for us.

\section{ACTION RESEARCH AND}

To understand the social, economic, political and environmental problems at the heart of this crisis, the Mali Elephant Project engaged the local people. A complete survey of everyone living and working around Lake Banzena enabled the project to gather data to understand the full demand on resources and the concerns and perceptions of the inhabitants and users. Once they had
the data, the project team then gathered

the local communities together to discuss the findings and crucially, to present this the context of their lives and the problems they face. This process also served a vital function of bringing the different to develop a shared vision of the problem and a collaborative plan for the future.

Community-based natural-resource management was at the heart of the plan. Each social group had its own system of

The rate of poaching from 2012 to 2019
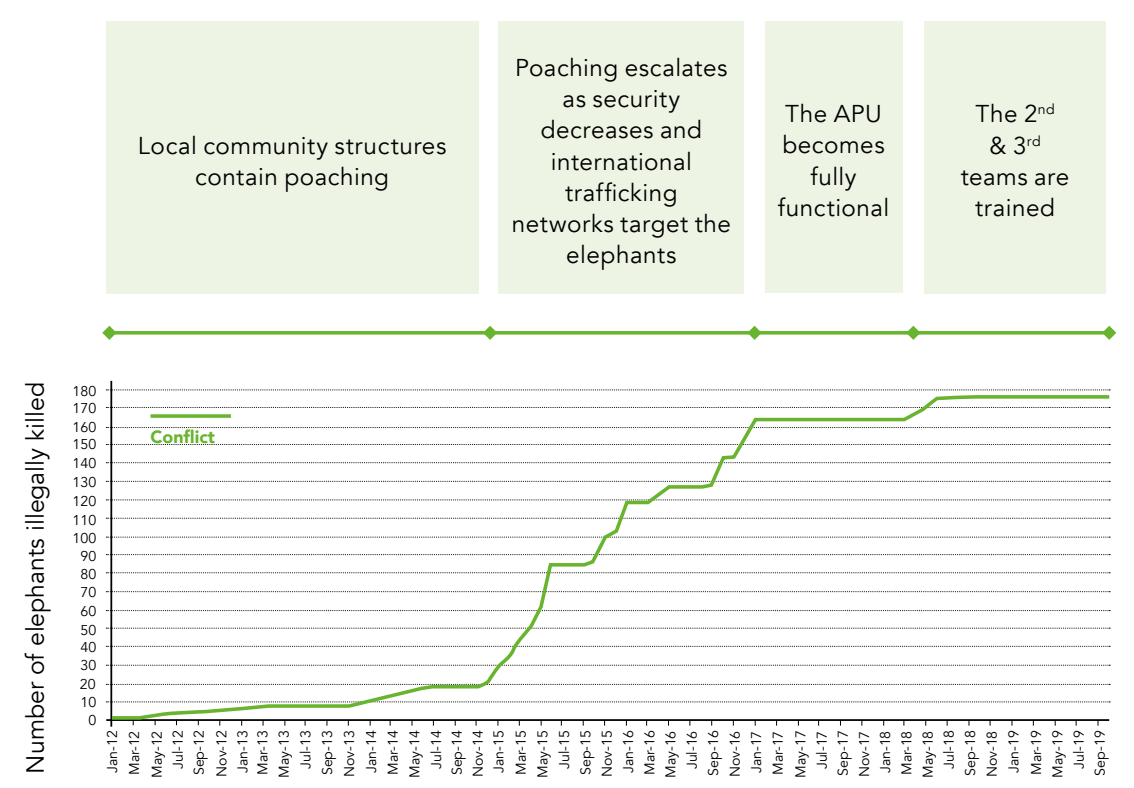

Poaching has incresed between 2012 and 2019 


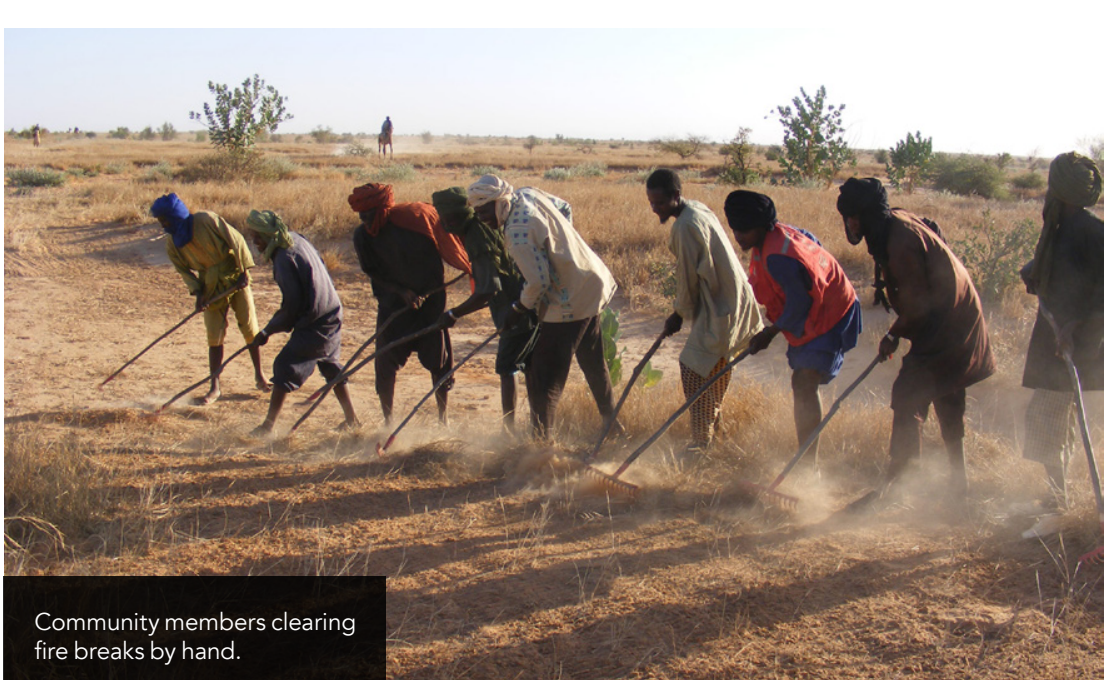

those of another group. However, they The collaborative approach between all also recognised that overexploitation - ethnictiles soon proved its worth when a was at the hart of the newly formed large pasture area - created that a collaborative approach to resource by two communities and protected by benefit. Built into this shared approach people had abundant pasture close to

Other communities began to reach out for help when they saw the benefits of a shared approach to resource management. was the acknowledgement of, and respect for, the needs of the elephants alongside rights, and their animals were healthier, their own. A representative management produced more milk and fetched more at market. Other communities from across establish the rules of resource use across the elephant range began to reach out the communities (which included the for help when they saw the benefits of setting aside and protection of elephant shared approach to resource management. habitat and migration routes), and deliver - The project also worked with women penalties; while teams of young men, to develop alternative livelihoods tha known as 'eco-guardians', were elected benefitted from resource protection,

The Mali Elephant Project philosophy

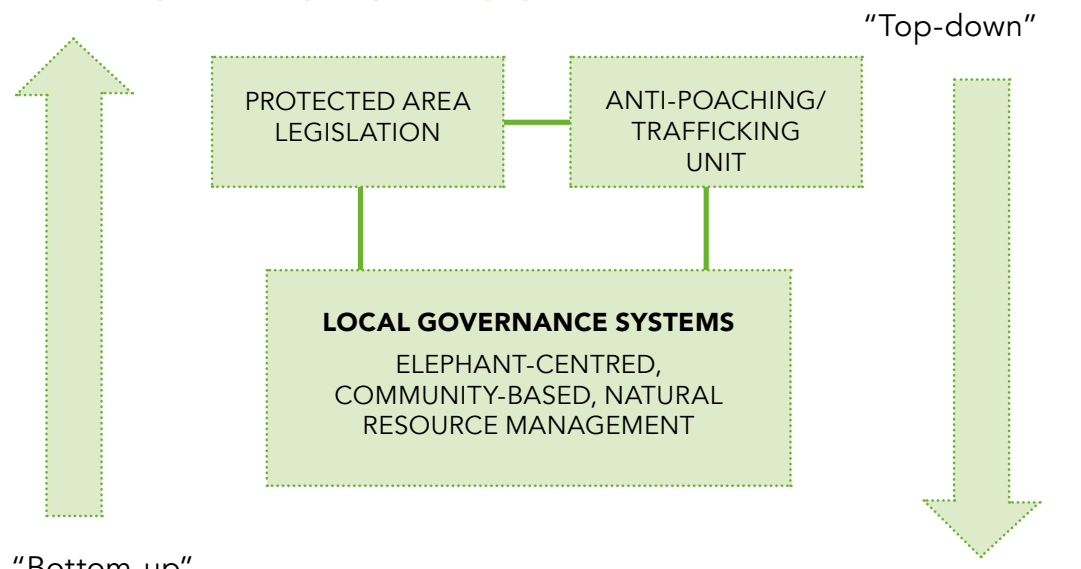

"Bottom-up"
Conflict and lawlessness brought present poaching. Whi ho govenn respond. The project again consulted local communities to discuss the proble in the context of the challenges they were facing and identify possible solutions. A particularly important initiative was the engagement of further eco-guards which provided an alternative to recruitment by armed groups and was also viewed by the young men as a more noble way to provide for their families and support their communities. The increase capacity for vigilance and habitat protection, along with the local sense of pride in the project limited poaching in the region.

\section{A MODEL FOR CO-EXISTENCE}

Despite the huge challenges facing the natural world, the Mali Elephant Project story with the possibility of a sustainable future. The project is continuing to work with local communities to embed sustainable resource-management. although the ongoing conflict makes this a much slower process. It also works with government to protect the entire elephant migration route and support communities to enforce lega protections, with the ultimate vision of being able to reintroduce lost species to restore the Sahel ecosystem.

Many conventional conservation tools were employed during this project. to use them in a way that fits with the context and continually adpts to the ever-changing situation. The long-term nature of the engagement with local communities is crucial to the survival and success of the project, particularly throughout the armed conflict and its divisive forces. Operating in such circumstances means additional time and resources are required to progress. Preconflict the shared recognition that human activity must respect ecosystem limits and that the elephants were an indicator of the health of the land, ensured the long-term sustainability and benefits of humanelephant interactions in Mali. During these thes of lawlessness it not only protects the elephants and restores degraded people in bettering their lives.

\section{Behind the Research}

\section{Dr Susan Canney}

E: susan.canney@zoo.ox.ac.uk T: +447796646604
W: https://www zoo ox.acuk/people/dr-susan-canney

Research Objectives

The Mali Elephant Project aims to find ways for humans and elephants to thrive together.

\section{Detail}

Susan Canney

Department of Zoology

Zoology Research and Administration sustainable development policy at

involves using systems perspectives

and collaborative approaches

Mansfield Road

to find sustainable solutions to

Oxford OX1 3sZ,

conservation problems.

Bio

Funding

Susan Canney is the Director of the Mali Elephant Project, having

conservation projects across

The project is a joint initiative of WILD

Foundation and the International

Other funders include:

European Uni

- Tusk Trust

- Evironment Facility \& UNDP

- US Fish and Wildlife Service

- The Elephant Crisis Fund

- Canadian Government \& United

Nations Multidimensional Integrated

Stabilization Mission in Mal

(MINUSMA)

\section{Collaborators}

Project Field Manager Nomba Ganame

\section{References}

Canney, S.M. (2019). The Mali Elephant Project: protecting elephants amidst conflict and poverty.
International Zoo Yearbook, 53 (1), 1-15.

Canney, S. and Ganame, N. (2013). Engaging youth and Com Nature \& Faune, 28 (1), 51-55.

\section{Personal Response}

Apart from the elephants, which other species have thrived as a result of the resource

II It has not been possible to establish rigorous monitoring systems for other species. However, multiple been an increase in gazelles in the pastoral areas under resource management and photographic evidence shows an increase in tree biomass and abundance in the woody

WILSB

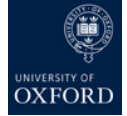
vegetation of forests under resource management.

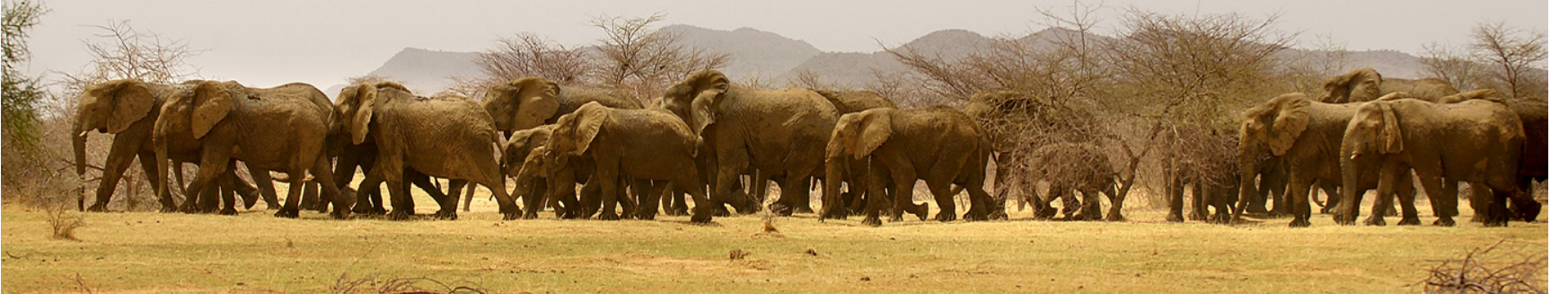

